\title{
Premissas em torno da desvalorização do magistério em análise: pelo que lutamos?
}

\author{
Bruno Deusdará \\ Universidade do Estado do Rio de Janeiro - RJ \\ Marisa Lopes da Rocha \\ Universidade do Estado do Rio de Janeiro - RJ
}

\begin{abstract}
Resumo
Neste texto pretendemos interrogar certos "consensos" que se estabelecem em torno da desvalorização do magistério, de modo que se possa ampliar o campo das lutas vinculadas à invenção de outros modos de trabalhar e viver na escola. A partir de uma perspectiva micropolítica e com base nas contribuições de Foucault e Deleuze, vimos discutindo a desvalorização do magistério em suas implicações com a institucionalização da produção de saberes e do trabalho de formação. Como conclusão, evidenciamos que, sob uma aparente convergência, residem diferentes leituras do que se passa e dos consequentes desafios cotidianos na singularização das práticas, acarretando desdobramentos e interferências nas políticas públicas.
\end{abstract}

Palavras-chave: Trabalho docente, desvalorização, micropolítica.

\section{Analysis of assumptions about devaluation of teaching profession: what do we fight for?}

Abstract

In this paper we intend to discuss some consensus around devaluation of teaching in the scope of the struggles involved in other forms of living and working at school. From a micro-politics view, the contributions of Foucault and Deleuze, we also discuss the devaluation of the teaching profession in the process of knowledge and job training institutionalization.In conclusion we show that, under the apparent convergence reside different readings of what is happening and the consequent challenges in everyday practice, encouraging developments and interference in public policy.

Keywords: Teaching work, devaluation, micro-politics.

\section{Premisas sobre la devaluación del magisterio en análisis: ¿por qué luchamos?}

\begin{abstract}
Resumen
En este texto se tiene la intención de interrogar ciertos "consensos" que se establecieron en relación a la devaluación del magisterio, de manera que se pueda ampliar el campo de las luchas relacionadas a la invención de otras formas de trabajar y vivir en la escuela. Desde una perspectiva micropolítica, a partir de aportaciones de Foucault y Deleuze, se viene discutiendo la devaluación del magisterio en su repercusión para la institucionalización de la producción de saberes y del trabajo de formación. Como conclusión se demuestra que bajo la aparente convergencia residen diferentes lecturas de lo que sucede y de los consecuentes desafíos cotidianos en la singularización de las prácticas, favoreciendo despliegues y interferencia en las políticas públicas.

Palabras clave: trabajo docente, desvalorización, micropolítica.
\end{abstract}




\section{Considerações inicias}

Quando o tema em pauta é educação, as opiniões apresentam-se nos mais variados matizes. É, no mínimo, curioso perceber que, não obstante a enorme variedade de divergências, haveria, em alguns pontos, convergência de opiniões. Entre essas opiniões aparentemente consensuais, desejamos destacar aqui aquelas que têm apontado para um processo crescente de desvalorização do magistério.

É preciso esclarecer que não pretendemos refletir acerca das causas históricas dessa desvalorização. Interessa-nos suspeitar das premissas que se fixam e, por consequência, se naturalizam, quando se diz, por exemplo, que a educação não vai bem porque hoje em dia não se respeita mais o professor. Em nossa opinião, se é verdade que as opções macroeconômicas têm feito os governos, nas diferentes esferas, sobreporem seus próprios interesses políticos e econômicos aos dos professores, os estudantes ou da educação como um todo, é verdade também que a necessária e urgente reposição das perdas salariais acumuladas nos últimos anos, por si só, não asseguraria todas as mudanças que desejamos. Parece-nos necessário avançar nos diversos campos de luta.

Se reconhecemos a necessidade de repor as perdas salariais, entre outros pontos das reivindicações dos sindicatos e dos movimentos sociais, que se mantiveram combativos nesses anos de "inverno", e participamos efetivamente das lutas em torno das reivindicações, de que avanços falamos? Muitos afirmam que ir adiante significa retomar as condições e o respeito devidos ao magistério. Ora, saudosismos à parte, o que se pretende restituir como valor perdido? Que imagens da profissão docente habitam as premissas que sustentam a vontade de retomar valores e reviver situações anteriores como possibilidade de mudança dos impasses atuais?

No desenho do panorama dos questionamentos que motivam a produção deste texto, cabe destacar que as polêmicas acerca da institucionalização das práticas de formação não são novas e vêm, ao longo do tempo, apresentando variações no campo das chamadas ciências humanas. A título de ilustração, transcrevemos a seguir um trecho de um livro inquietante, intitulado "A sociedade sem escolas", de Ivan Illich (1973), cujas afirmações são ainda extremamente atuais:

Muitos estudantes, especialmente os mais pobres, percebem intuitivamente, o que a escola faz por eles. Ela os escolariza para confundir processo com substância. Alcançando isto, uma nova lógica entra em jogo: quanto mais longa a escolaridade, melhores os resultados; ou, então, a graduação leva ao sucesso. O aluno é, assim, "escolarizado" a confundir ensino com aprendizagem, obtenção de graus com educação, diploma com competência, fluência no falar com capacidade de dizer algo novo. Sua imaginação é "escolarizada" a aceitar serviço em vez de valor. Identifica erroneamente cuidar da saúde com tratamento médico, melhoria da vida comunitária com assistência social, segurança com proteção policial, segurança nacional com aparato militar, trabalho produtivo com concorrência desleal. Saúde, aprendizagem, dignidade, independência e faculdade criativa são definidas como sendo um pouquinho mais que o produto das instituições que dizem servir a estes fins; e sua promoção está em conceder maiores recursos para administração de hospitais, escolas e outras instituições semelhantes (Illich, 1973, p. 21).

Cabe salientar que, a nosso ver, o conjunto das propostas constantes no referido livro configura um indicador das tensões mundialmente vivenciadas nos anos sessenta e setenta. Não obstante, não é por corresponder aos embates de uma conjuntura que já não é a nossa - uma vez que não vivemos hoje com tamanha intensidade as efervescências sociais - que o trecho acima deixará de ser intrigante. É perturbador - e, por isso, torna-se imprescindível como reflexão - imaginar que estamos "escolarizando" ao confundir notas e rendimentos com os processos vivenciados. É inquietante pensar que a escola não cessa de nos convocar a "recuperar" alunos, quando os problemas atribuídos a eles individualmente acabam por corresponder a efeitos produzidos por nossas próprias práticas.

Façamos Veiga-Neto (2006) entrar em cena para um diálogo com Illich, ao afirmar que "a educação escolar pode funcionar como uma arena para as lutas permanentes de invenção e imposição de sentidos, seja pela manutenção, seja pela mudança dos regimes de verdade e das ordens discursivas que os alojam" (Veiga-Neto, 2006, p. 88).

O confronto entre essas duas posições, antes de nos convocar a tomar partido, parece abrir um cenário de questionamentos que faz do trabalho na escola um exercício simultâneo de lutas - haja vista a metáfora da "arena" - e de desconfianças - já que é preciso suspeitar do que estamos produzindo na escola como possibilidade de renovação das nossas próprias apostas/lutas.

É nos interstícios dessa polêmica que tal empreendimento, inspirado na genealogia foucaultiana, encontraria uma "massa" de textos e práticas acumulados, material ao qual o historiador do presente compareceria com parcimônia e suspeita. Ele começaria nos interrogando o que estamos ajudando a fazer de nós mesmos - como psicólogos ou como professores - e de nossos alunos na escola. Confessa não estar interessado nas origens da profissão docente, mas nos arranjos que essa atividade compõe. Substitui questões como "O que é o trabalho do professor?" por outras, por exemplo, "Como certos sentidos sobre o magistério se tornaram verdadeiros?"; ou "Que efeitos essa verdade produz?".

O propósito do presente artigo consiste em pensar o que se configura hoje como "desvalorização do magistério", considerando-se os contornos do trabalho docente no cotidiano escolar. Nosso desafio é, através de uma abordagem micropolítica das práticas de formação em que cabe interrogar de que modo os processos de institucionalização se atualizam na escola, compreender a aposta predominante em uma "revalorização" do lugar de professor. Ao mesmo tempo, a atenção aos processos de institucionalização, 
em vez de neutralizar as tensões que afetam a todos e a cada um, pode favorecer a criação de um campo coletivo de análise-intervenção que interfira nas condições a favor da ampliação da qualidade de vida no exercício do magistério.

\section{Institucionalização das práticas de formação: ou "como certos sentidos se tornaram verdadeiros?"}

Em Foucault (1973/2005) o tema da verdade é tratado sempre em articulação com os processos que a instituem como tal. A premissa no referido tratamento é a de que não há correspondência unívoca entre os saberes e o mundo que, segundo a versão ocidental, esses saberes viriam representar; ou seja, para Foucault (2005), os saberes não seriam conteúdos que "reapresentariam" um mundo precedente. Essa negativa tem uma dupla motivação: incide tanto sobre o pressuposto de que o saber se reduziria a um conteúdo, quanto sobre aquele que procuraria garantir uma relação de anterioridade do mundo em relação ao saber.

Em relação ao primeiro aspecto, isto é, a rejeição dos saberes como conteúdos, recorremos ao Deleuze (1986/2005), leitor de Foucault. Segundo o referido autor, essas "camadas sedimentares" que seriam os saberes são formadas de regiões de visibilidades e campos de legibilidade. Deleuze, na mesma obra, propõe uma sistematização das duas "metades" do saber, com inspiração em Hjelmslev, afirmando que conteúdo não se reduz a significado. Segundo ele, as regiões de visibilidade, ou "conteúdo", e os campos de legibilidade, ou "expressão", conteriam uma forma e uma substância. Seus exemplos remetem às análises foucaultianas das práticas de encarceramento e vigilância: o conteúdo teria como forma a prisão e como substância, os "presos", que são "vistos" a partir de certa condição; já a expressão teria como forma o direito penal, e como substância, a "delinquência" enquanto objeto dos discursos.

Esses exemplos nos interessam, sobretudo, por evidenciarem o grau das relações estabelecidas entre visibilidades e enunciabilidades. Embora se acredite haver correspondência entre o que se diz e o que se vê, Foucault definirá essa aparente correspondência como efeito das práticas.

A respeito dessa questão, Deleuze (1986/2005) nos diz:

Há uma abundância de questões que constituem, de cada vez, o problema da verdade. O Uso dos Prazeres tira a conclusão de todos os livros precedentes quando mostra que o verdadeiro só se dá ao saber através de "problematizações" e que as problematizações só se criam a partir das "práticas", práticas de ver e práticas de dizer. Essas práticas, o processus e o procedimento (procédé) constituem os processos (procédures) do verdadeiro, "uma história da verdade". Mas é preciso que as duas metades do verdadeiro entrem em relação, problematicamente, no próprio instante em que o problema da verdade exclui sua correspondência ou sua conformidade (Deleuze, 1986/2005, p. 72-73)
Se não há conformidade entre "ver" e "falar", como se dá a relação problemática entre essas "duas metades do verdadeiro"? Esse questionamento, em alguma medida, remete-nos ao segundo aspecto anunciado no início deste item, já que os efeitos de verdade são correlatos das relações de poder. Desse modo, os saberes, como formações históricas, são inseparáveis das condições de sua emergência. Para Foucault, a "vontade de saber" não se reduz à natureza humana.

Com Nietzsche, Foucault (1973/2005) dirá que o ato de conhecer é, em algum sentido, uma violência, já que não haveria qualquer relação de continuidade entre a coisa conhecida e o saber produzido sobre ela. Essa não continuidade entre conhecimento e mundo é sustentada, por um lado, na consideração de que o mundo não teria uma predisposição para ser conhecido, e, por outro, a "vontade de saber" não se atualizaria como dimensão instintiva:

O conhecimento foi, portanto, inventado. Dizer que ele foi inventado é dizer que ele não tem origem. É dizer, de maneira mais precisa, por mais paradoxal que seja, que o conhecimento não está em absoluto inscrito na natureza humana. O conhecimento não constitui o mais antigo instinto do homem, ou, inversamente, não há no comportamento humano, no apetite humano, no instinto humano, algo como um germe do conhecimento (Foucault, 1973/2005, p.16).

Neste trecho a abordagem foucaultiana parece nos oferecer uma síntese de sua concepção sobre a relação entre o saber e o mundo, remetendo-nos aos jogos de força que se constituem sócio-historicamente. Aqui nos interessa pensar nos desdobramentos das questões, enfatizando, a partir da concepção de que as relações entre o saber e o mundo se dão por in(ter)venção, os processos de institucionalização da produção de conhecimento.

Vejamos, então, de que modo os pressupostos explicitados anteriormente se atualizam nas análises dos processos de institucionalização. Ao retomar a ideia recorrente segundo a qual o século XVIII teria sido o momento da emergência dos saberes técnicos, Foucault (2002) vai propondo uma análise que parece desmontar a versão "oficial" dessa emergência. Não se trata, como argumenta ele, de fazer convergir um conjunto de iniciativas, ou de um movimento em direção única, um progresso em que a ignorância estaria cedendo lugar ao conhecimento. Ao contrário, a existência de saberes é múltipla: em vez da suposta convergência, os saberes variariam segundo as regiões geográficas, a dimensão das oficinas e das indústrias nas quais eram produzidos, etc., conformando uma dispersão entre os saberes. Tal dispersão indicaria o funcionamento da produção de conhecimento, "numa sociedade em que o segredo do saber tecnológico valia riqueza e em que a independência desses saberes, uns em relação aos outros, significava também a independência dos indivíduos" (Foucault, 2002, p. 214)

Nesse contexto em que a multiplicidade de saberes encontra-se em luta - uma luta econômico-política, já que 
esse saber-segredo significava "riqueza" material e "independência" individual -, desenvolvem-se processos de "anexação, de confisco, de apropriação dos saberes menores, mais particulares, mais locais, mais artesanais, pelos maiores" (Foucault, 2002, p.215). Esses processos contarão com um grau de intervenção do Estado, mesmo que indiretamente. A intervenção do Estado nessa luta dos saberes se dará, segundo o autor, a partir de quatro procedimentos.

O primeiro deles consiste em desqualificar os saberes dispendiosos economicamente, os saberes irredutíveis. Esse procedimento de desqualificação irá produzir a eliminação de saberes que não tenham sido produzidos no interior de um campo de regras institucionalmente reconhecido, dando consistência à dicotomia saberes teóricos / saberes da prática, bastante familiar ao racionalismo ocidental.

O segundo procedimento reside em pretender romper as barreiras do segredo, permitindo o intercâmbio entre os saberes. Para isso é preciso criar escalas de correspondência entre saberes, é preciso torná-los intercambiáveis, ajustáveis uns aos outros. Com efeito, tais procedimentos de ajustes e correspondências produzirão, ao lado da desqualificação / eliminação dos saberes da prática, um grau de normalização dos saberes. Ao criar formas de correspondência, ou seja, ao quebrar as fronteiras produzidas pelo segredo, de um lado, pretende-se constituir universalidade, ampliando as regiões sobre as quais os saberes passam a incidir, e, de outro, assiste-se ao desenvolvimento de novas formas de controle da produção de conhecimento.

A lógica universalizante de produção de conhecimento subjacente à normalização dará lugar, simultaneamente, a um terceiro procedimento: o de classificação hierárquica dos saberes. Uma vez desqualificados e eliminados os saberes tidos como "menores" e estabelecidos os procedimentos de normalização, promove-se uma hierarquização dos saberes, de modo que possam se diferenciar aqueles que seriam mais específicos de outros, mais gerais. Essa hierarquização parece proceder a operações de abstração.

O quarto procedimento é o da centralização dos saberes. Parece garantir-se a axiomatização, produzindo uma organização interna dos saberes. Os quatro procedimentos assim descritos fazem do século XVIII o momento em que, a despeito de uma versão "oficial", que asseguraria a evolução da sua produção, isto é, um avanço gradual do conhecimento sobre a ignorância, jogos de forças acabam por produzir disciplinamento dos saberes.

O século XVIII foi o século do disciplinamento dos saberes, ou seja, da organização interna de cada saber como uma disciplina tendo, em seu campo próprio, a um só tempo critérios de seleção que permitem descartar o falso saber, o não-saber, formas de normalização e de homogeneização dos conteúdos, formas de hierarquização e, enfim, uma organização interna de centralização dos saberes em torno de um tipo de axiomatização de fato. Logo, organização de cada saber como disciplina e, de outro lado, escalonamento dos saberes disciplinados do interior, sua intercomunicação, sua distribuição, sua hierarquização recíproca numa espécie de campo global ou de disciplina global a que chamam precisamente a 'ciência (Foucault, 2002, p. 217-218).

Essa análise histórica da institucionalização dos saberes parece nos abrir um campo de interrogações sobre os procedimentos de disciplinamento que dão um cadenciamento à formação escolar que as vozes em torno da denúncia de "desvalorização do magistério", pelo menos a princípio, não iluminam. O nosso desafio nas lutas sociais residiria, então, em não nos restringirmos às denúncias. Se, por um lado, é possível operar com elas a nosso favor, dando a conhecer as condições de precariedade às quais nos submetemos cotidianamente, por outro, não podemos ignorar que a denúncia de "desvalorização do magistério" pode ser capturada pela expectativa de que "revalorizar" significaria a restituição de um lugar de destaque para o professor, resolvendo muitas das tensões vivenciadas na escola.

Nesse contexto, a suposta manutenção de um lugar para o professor parece alimentar-se de alguns dos procedimentos de disciplinamento descritos anteriormente, sobretudo a desqualificação dos saberes da prática. De que modo tais procedimentos podem criar efeitos indesejáveis para o agenciamento de novas práticas para uma nova Educação?

Podemos pensar na fragilização do poder de intervenção da comunidade escolar na invenção do cotidiano pela cristalização no uso do tempo-espaço da formação que dá um aspecto repetitivo ao trabalho docente, o qual se torna entediante para o aluno, provocando tensão na relação entre os educadores e as famílias, sendo estas desqualificadas quanto aos saberes produzidos em condições que não as dos rituais acadêmicos. São relações despotencializadoras em que se espera a resolução dos "problemas" diagnosticados por uma lógica que, desqualificando a produção coletiva da vida escolar, legitima as marcas de assujeitamento (Rocha, 2001). Afirma este autor:

Isso se dá na medida em que é justamente na ordem da hierarquia, das dicotomias teoria e prática, pensador e técnico, professor e aluno, ensino e aprendizagem, que se constroem as segmentações entre as políticas educacionais de gabinete, as condições cotidianas do trabalho escolar (caracterizado pelo isolamento e assoberbamento de tarefas) e a própria formação dos profissionais da educação, que não se estabelece através da construção de análises no dia-a-dia educacional (Rocha, 2004, p.187).

Assim, a mesma lógica que, na escola, tem sido responsável por enredar a comunidade em rituais escolarizados dos saberes e códigos há muito estabelecidos como objetivos, coerentes, verdadeiros e válidos para o aprimoramento do homem e a preparação para a vida, atualiza-se na formação docente, enfatizando uma noção de competência como execução eficiente do previsto. 
Nesse quadro, parece emergir outro conjunto de questões que nos conduzem a pensar os efeitos dos procedimentos de disciplinamento dos saberes na constituição de um "território" para o trabalho docente (Rocha, 2007).

\section{Contornos do trabalho docente: ou "que efeitos essa verdade produz?"}

Neste item vamos argumentar no sentido de pôr em suspenso os efeitos emergidos a partir do século XVIII que estão implicados com a institucionalização dos saberes sustentada no exercício de disciplinamento da formação e do trabalho docente. Em tal processo, a formação teria como meta a erudição, em que se atualiza a expectativa de acúmulo de um saber-repetição, através do agenciamento de porta-vozes dispostos a consumir esses saberes (Rocha, 1998). Isso implica rituais de ensino-aprendizagem circunscritos a uma organização do tempo e do espaço vinculados à sala em que se realiza a aula. Nem a função pedagógica que atravessa a escola tradicional, nem a Escola Nova e o tecnicismo contemporâneo, modificaram nas grandes redes de ensino público, as condições e expectativas dos corpos dispostos em série, do silêncio, da atenção ao professor, das avaliações, enfim, dos modos de controle que delimitam o que é trabalho do professor e o que é trabalho do aluno.

Queremos refletir acerca dos contornos do trabalho docente de hoje, analisando que dimensão das atividades de formação extrapola as imagens classicamente identificadas com ele. Se nos constituímos numa complexa rede dialógica a partir da qual sentidos e práticas produzem a realidade, que critérios podemos utilizar para estabelecer em que consiste o trabalho docente?

Talvez devêssemos olhar para a escola. Que limites damos à nossa atividade profissional? Por que definimos que, ao menos em grande parte, nosso trabalho se restringiria à sala de aula, se, para que uma aula aconteça é fundamental que diferentes ações sejam processadas? Os efeitos da lógica de disciplinamento dos saberes, por um lado, reduzem-se às coordenadas de espaço-tempo da sala de aula e, por outro, implicam-nos com a desqualificação de um conjunto de atividades por nós desenvolvidas que estão relacionadas com as práticas de formação, mas não ganham visibilidade como trabalho (Deusdará, 2006). Que outra concepção de produção de saber é preciso desenvolver para que tais atividades sejam qualificadas? Ou ainda, como afirmar a formação como ato, considerando-se as suas condições de realização? Ampliar a dimensão de intervenção do professor e do aluno em cena não traria novas perspectivas para um pensar/fazer inventivo?

Que tal nos depararmos com um Foucault-professor que discute "o que é um curso"? Convidamos o leitor a uma incursão na primeira aula do curso ministrado por M. Foucault nos anos de 1975 e 1976, no Collège de France, intitulado "Em Defesa da Sociedade" (Foucault, 2002). Nessa aula o autor nos fala da dinâmica dos cursos no Collège de
France: ele se utiliza dos seminários como forma de prestar contas publicamente de sua atividade de pesquisa.

A esse respeito ele propõe o seguinte questionamento: "De que maneira se pode manter a par aqueles que podem se interessar por ela [a pesquisa] e aqueles que têm alguns motivos de estar ligados a essa pesquisa?" (Foucault, 2002, p.3). Como não ler nesse questionamento também um convite à reflexão acerca das formas de institucionalização dos saberes de que tratará em aulas posteriores do curso? Como não nos perguntar também acerca das nossas implicações com isso, ou seja, com uma luta pela ativação de dispositivos de produção e de publicização das pesquisas? O que se constitui como uma aula-pesquisa? Não seria fazer da sala de aula um possível laboratório de experimentação de ideias, compartilhamento, algo como saberes em discussão, provocação, desafio do outro a pensar a história do já constituído e suas implicações no presente, pois Foucault está falando do fazer, de convocar o pensamento, e não somente de divulgar pesquisas.

$\mathrm{Na}$ escola esse questionamento parece inverter-se. Não nos perguntamos mais como podemos nos dirigir àqueles aos quais nossos saberes podem interessar. Não nos interrogamos mais acerca dos possíveis motivos de estarmos ligados. De certa forma, o vínculo que nos mantém em cena parece naturalizar-se, quando o que está em jogo é despertar o interesse do aluno para compor a cena. A abertura para alternativas a essa naturalização dos vínculos que nos ligam na escola demanda o investimento em outras formas de apropriação do espaço-tempo. Nesse ponto, Foucault nos surpreende ao ressaltar que se sente obrigado a dizer o que está fazendo - não para conquistar seguidores, mas talvez para fazer do vínculo um dispositivo de movimento, sempre se esforçando para continuar a dirigir-se a alguém, para fazer bons encontros.

Foucault faz uma observação simples que dá visibilidade à dimensão do outro numa prática de aula-pesquisa e isso nos chama a atenção: "Considero-me absolutamente obrigado, de fato, a dizer-lhes aproximadamente o que estou fazendo, em que ponto estou, em que direção vai este trabalho; e, nessa medida, igualmente, considero-os inteiramente livres para fazer, com o que eu digo, o que quiserem" (Foucault, 2002, p.4).

No trecho acima, parece falar o Foucault que lemos em "A Arqueologia", tão implicado com o tema das descontinuidades, já que as continuidades somos nós que construímos inventando sentidos, fortalecendo modos de fazer e de entender o que se passa. Isso, certamente, não se faz fora das condições e circunstâncias em que vivemos, fora de uma história que vimos produzindo com o(s) outro(s). Ele saberia então que não está oferecendo caminhos a serem seguidos. Haveria sempre pequenas rupturas, desvios, distorções, pois, uma vez que nos inscrevemos na alteridade, é esse outro que compõe comigo um território de indagação. Quando é que a sala de aula se constitui em um espaço-tempo que implica num coletivo, que convida a pensar? 
Nesse aspecto, ele coloca a seu público sua disposição de refletir, compartilhando uma caixa de ferramentas. Isto é o que chamamos de formação em ato! Parece-nos oferecer evidências das críticas que fará nas aulas seguintes sobre as operações com que está às voltas para construir um caminho possível de entendimento. Concomitantemente, o que fica em questão é o disciplinamento dos saberes: seleção dos saberes válidos diante de uma região de saberes falsos, de normalização e homogeneização dos conteúdos de uma disciplina, de hierarquização e centralização.

Ele parece também saber que, como autor a quem se atribui uma série de reflexões, ele não é, ele funciona, (re)faz; e esse funcionamento abrangeria não apenas o que ele próprio diz, mas tudo o que é feito com ele. Foucault é também o que dizemos dele e o que fazemos com ele, já que, assim como as ferramentas se marcam dos usos que fazemos delas, os autores parecem se impregnar dos discursos a cada vez que deles fazemos uso, assim como do que circula em torno deles e das apropriações que são feitas. Ao contrário do que é pensado comumente, dar uma aula, fazer circular um determinado assunto, é pôr em funcionamento um dispositivo, e não somente falar de um conteúdo. É perder o controle, pois no momento em que a aula cria sintonia a produção se torna coletiva. O que é, então, essa aula, senão pôr em jogo saberes, uma certa genealogia? Ele põe em questão o poder como exercício, que ele ativa quando entra em cena nos seminários do mesmo modo que nas lutas que vão se travando (por lugares na sala, pelo horário e os usos decorrentes dos seminários, etc.). Mesmo antes de falar sobre ela, vai aparecendo uma genealogia do exercício de poder que tem o seminário como um dispositivo; uma genealogia como tática que faz intervirem, a partir das discursividades locais descritas pela arqueologia, os saberes dessujeitados que daí se desprendem.

Ao ser indagado sobre a atividade do professor, Deleuze (1996, p. 69) fala de ensaio e inspiração, de fascínio e acolhimento à matéria da qual tratamos, evidenciando que "se não tivermos ensaiado o bastante, não estaremos inspirados. Uma aula quer dizer momentos de inspiração, senão não quer dizer nada." No abecedário letra P declara:

É preciso estar totalmente impregnado do assunto e amar o assunto do qual falamos. Isso não acontece sozinho. É preciso ensaiar, preparar. É preciso ensaiar na própria cabeça, encontrar o ponto em que... É muito divertido, é preciso encontrar... É como uma porta que não conseguimos atravessar em qualquer posição. (...) O que faz parte do papel do professor é o que eu disse sobre o ensaio anterior e a inspiração. Esse é o papel do professor (Deleuze, 1996, p.71).

Voltemos ao trecho bastante provocativo, em que Foucault nos "decreta" livres para usarmos seu referencial como acharmos melhor. Impossível não atribuir também a esse trecho um sarcasmo, presente em vários momentos de seu texto. Somos livres para usá-lo como achamos melhor não porque tenhamos um decreto seu, mas porque o uso que fazemos dos saberes se dá sempre em condições que nunca são correspondentes àquelas em que esses saberes são elaborados pelo seu autor. É preciso sempre fazer acertos, desdobramentos, pensar em mais um critério, confrontar com outras coisas, enfim, colocar em cena um conjunto de saberes que tradicionalmente são vistos como secundários, ou seja, tudo aquilo que a gente deve colocar em notas de rodapé ou nos capítulos de metodologia. As circunstâncias são sempre empurradas para o canto, onde não nos seria possível pôr em xeque as influências e continuidades que reivindicamos para nos legitimar como enunciadores do discurso de uma disciplina.

Talvez Foucault estivesse nos provocando, e a polarização não residisse numa condição de estar preso ou livre, mas nas lutas que travamos com os saberes, através de dispositivos que tragam para a "cena" os saberes sujeitados, justamente os que fazem da aula intervenção, encontro, autoria de muitos, e do trabalho docente um exercício ético-estético, ativando condições de emergência de saberes. Como? Ensaiar é trabalho, inspirar é condição para que uma aula aconteça.

\section{Fazendo deslizar os contornos do trabalho docente: ou "a formação como acontecimento"}

Este texto é motivado por uma inquietação: uma suposta convergência entre os atores sociais envolvidos com a temática da Educação apontando a "desvalorização do magistério" como um indicador importante para pensar a situação atual. Essa inquietação nos levou a interrogar quais seriam as premissas em torno da construção de alternativas para a Educação. Nossa aposta inicial residiria em apontar que, sob uma aparente convergência, residem diferentes leituras do que se passa e dos consequentes desafios em questão. Retomamos as análises de Foucault acerca da institucionalização dos saberes em curso no século XVIII para pensar com que processos estamos nos implicando ao encaminhar nossas lutas nos pautando apenas por um denuncismo que almeja dar destaque à figura do professor e às condições de trabalho. Voltamos a evidenciar que não se trata de desqualificar tais reivindicações, pois essas lutas são fundamentais; mas pretender recuperar um valor perdido para o magistério sem levar em consideração a dimensão micropolítica nos associa aos procedimentos de desvalorização dos saberes da prática, o que tem possibilitado poucas alianças efetivas no cotidiano escolar.

Em seguida, colocamos em discussão contornos que habitualmente atribuímos ao trabalho docente. Com isso, buscamos discutir os efeitos de sentido produzidos por discursos, ao apagar uma dimensão importante das atividades de trabalho do professor vinculadas ao exercício ético-estético que desafiam o acolhimento das diversidades e diferenças como parte do processo de ensinar-aprender. Tais práticas reivindicam uma política de formação no curso das ações e da vida que coloque em cena coletivos em pesquisa-intervenção, demandado outro uso qualitativo do 
tempo e do espaço. Parece-nos interessante ressaltar que as denúncias de desvalorização do magistério, para que possam abrir outros caminhos de discussão e potencializar uma intervenção coletiva nas tensões geradas no cotidiano, devem, de algum modo, apontar para o conjunto de atividades que são silenciadas, tais como selecionar/escrever textos, criar materiais, planejar estratégias e engendrar alternativas no que tange não apenas aos conteúdos, mas também às atitudes, entre outras.

Nosso propósito aqui é incrementar discussões a partir das quais seja possível analisar não apenas as premissas que subjazem à suposta convergência de opiniões em torno da "desvalorização do magistério", permitindo pensar que processos de produção de verdade estão implicados ao assumirmos tal questão como indicador da crise e disparador de lutas. Foi nesse sentido que argumentamos que o eixo da desvalorização do magistério, de algum modo, precisa estar associado a um conjunto de outras propostas de intervenção micropolítica, tais como a valorização dos encontros que viabilizam ensaios e inspiração, como diz Deleuze, ou produções que façam diferença como em Foucault. Avaliação, condições de trabalho, velhas e novas tecnologias, leitura, escrita, fracasso escolar são temáticas que devem ser problematizadas pela comunidade escolar, fazendo deste exercício uma luta coletiva por uma nova Educação. Consideradas como horas de trabalho tanto quanto os momentos de interação professor-aluno em sala de aula, o objetivo é que tais proposições favoreçam práticas de intervenção no cotidiano escolar, afirmando uma atuação que não se restrinja à ação dos professores. Os desafios cotidianos há muito estão postos e exigem práticas singulares que só podem ser produzidas pelos implicados, favorecendo desdobramentos e interferências nas políticas públicas, em uma concepção de público que fala de todos a partir de cada um, de qualquer um que se disponha a fazer parte do campo de experimentação como um ato potencializador de mudanças.

Se as denúncias constituem uma tática necessária, sobretudo em países como o Brasil, em que os poderes responsáveis não têm sido capazes de garantir a todos as condições socioeconômicas básicas de sobrevivência, ao colocar em discussão o exercício de direitos fundamentais, isto parece intensificar nosso desafio em procurar construir alianças para a construção de alternativas. "Existem momentos em que estas simplificações são necessárias. Para de tempos em tempos mudar o cenário e passar do pró ao contra, um tal dualismo é provisoriamente útil" (Foucault, 1979/1998, p. 238).

Prossegue o autor:

É preciso passar para o outro lado - o "lado correto" mas para procurar se desprender destes mecanismos que fazem aparecer dois lados, para dissolver esta falsa unidade, a "natureza" ilusória deste outro lado de que tomamos o partido. É daí que começa o verdadeiro trabalho, o do historiador do presente (Foucault, 1979/1998, p. 239).

\section{Referências}

Deleuze, G. (1996). O Abecedário. Entrevista com Claire Parnet. Recuperado: 02 ago 2010. Disponível: http://www.scribd.com/ doc/7134415/o-Abecedario-de-Gilles-Deleuze-TranscricaoCompleta

Deleuze, G. (2005). Foucault. (3a ed., Claudia Sant'Anna Martins, trad.). São Paulo: Brasiliense. (Trabalho original publicado em 1986)

Deusdará, B. (2006). Imagens da alteridade no trabalho docente: enunciação e produção de subjetividade. Dissertação de Mestrado, Universidade do Estado do Rio de Janeiro, Rio de Janeiro-RJ.

Foucault, M. (1998). Microfísica do poder (Roberto Machado, trad.). Petrópolis, RJ: Vozes. (Trabalho original publicado em 1979)

Foucault, M. (2002). Em Defesa da Sociedade (Maria Ermatina Galvão, trad.). São Paulo: Martins Fontes.

Foucault, M. (2005). A Verdade e as formas jurídicas. (3a ed., Roberto C. de M. Machado \& Eduardo J. Morais, trads.). Rio de Janeiro: Nau. (Trabalho original publicado em 1973)

Illich, I. (1973). A sociedade sem escolas. (2a ed., Lúcia Mathilde Endlich Orth, trad.). Petrópolis, RJ: Vozes.

Rocha, M. L. (1998). Para além das evidências, dos princípios e dos valores instituídos no fazer pedagógico. Cadernos Transdisciplinares do Instituto de Psicologia da UERJ, 1, 71-80.

Rocha, M. L. (2001). Formação e prática docente: implicações com a pesquisa-intervenção. Em I. Maciel (Org.), Psicologia e Educação: novos caminhos para a formação (pp. 175-191). São Paulo: Ciência Moderna.

Rocha, M. L. (2004). A Formação a Interface Psicologia/Educação: novos desafios. Em D. Mancebo \& A. M. Jacó-Vilela (Orgs.), Psicologia Social: abordagens sócio-históricas e desafios contemporâneos (2a ed. pp. 185-196). Rio de Janeiro: EdUERJ.

Rocha, M. L. (2007). A formação como acontecimento: solidão, pensamento e autogestão. Em A. M. Machado, Â. M. D. Fernandes \& M. L. da Rocha (Orgs.), Novos possíveis o encontro da psicologia com a educação (pp. 37-48). São Paulo: Casa do Psicólogo.

Veiga-Neto, A. (2006). Na oficina de Foucault. Em W. O. Kohan \& J. Gondra (Orgs), Foucault 80 anos. Belo Horizonte: Autêntica. 
Recebido em: $27 / 03 / 2012$

Reformulado em: 07/08/2012

Aprovado em: 17/11/2012

Sobre os autores

Bruno Deusdará (brunodeusdara@gmail.com)

Doutor em Psicologia Social (UERJ)

Endereço: R. Mariz e Barros, 1098 / 307 - Tijuca - Rio de Janeiro - RJ, CEP: 20.270-002.

Marisa Lopes da Rocha (marisalrocha@uol.com.br)

Doutora em Psicologia (PUC-SP)

Endereço: R. Mario Bouças Coimbra, 10, BI 2, apto 501 - Jacarepaguá - Rio de Janeiro - RJ.

CEP: 22743-675 